\title{
Drafters, Engineering, and Mapping Technicians
}

National Cancer Institute

\section{Source}

National Cancer Institute. Drafters, Engineering, and Mapping Technicians. NCI

Thesaurus. Code C122442.

Workers who use software to convert the designs of engineers and architects into technical drawings and plans. 